\title{
Is Lockdown Effective Against Fatality of COVID-19?
}

\author{
Yuka Ikeda, Ai Tsuji, Mutsumi Murakami, Yasuko Kitagishi and Satoru Matsuda* \\ Department of Food Science and Nutrition, Nara Women's University, Kita-Uoya Nishimachi, Nara 630-8506, Japan
}

*Corresponding author: Satoru Matsuda, Department of Food Science and Nutrition, Nara Women's University, Kita-Uoya

Nishimachi, Nara 630-8506, Japan

\begin{tabular}{|c|c|}
\hline ARTICLE INFO & ABSTRACT \\
\hline Received: 幽 July 06, 2020 & Citation: Yuka Ikeda, Ai Tsuji, Mutsumi Murakami, Yasuko Kitagishi, Satoru Matsuda. Is \\
\hline Published: 㓞 July 17, 2020 & $\begin{array}{l}\text { Lockdown Effective Against Fatality of COVID-19?. Biomed J Sci \& Tech Res 28(5)-2020. } \\
\text { BJSTR. MS.ID.004729. }\end{array}$ \\
\hline
\end{tabular}

\section{Editorial}

COVID-19 had been declared a pandemic in March 2020, triggering huge human victims and serious economic loss. The COVID-19 spreads in the population at a rate of $0.8-3 \%$ and mostly affects elder men. At the beginning of the pandemic, case fatality rate was calculated up to be $2.2 \%$ [1]. From this epidemical data, COVID-19 was considered as a disease that should not be lifethreatening for more than a little percentage of all infected people. Afterwards, there is a regional difference in the meaning of severity and/or comprehensive fatality over the globe. In particular, the people of Italy, Spain, France, UK, USA and other countries with the most advanced health care system have been suffering large losses. Even in Japan with relatively low rates of COVID-19 infection, the fatality-rate on the prefectures of Hokkaido ( 8 \%) and/or Gunma $(\sim 12 \%)$ seems to be high compared to that of Kagoshima (0\%) and/or Yamagata (0\%), from statistics data released by the Ministry of Health, Labour and Welfare in Japan, June 2020. Additionally, an infrequent number of children developed a more serious inflammatory disorder with similar to Kawasaki disease-symptoms at the same time during COVID-19 pandemic. It is for sure that some of the deaths observed during the pandemic may need to be reclassified later and the levels will be attributed to actual COVID-19 [2]. For example, there may be diagnostic problems within primer specificity and sensitivity on the real time PCR test by using throat swab sample for the diagnosis. Is that real COVID-19 excluding other corona-viruses infection? Anyway, development of strategies to hold the virus-spread and aggravation should be mandatory.

Social lockdown and effective vaccine could have drastic impacts on severe viral infections even in the filovirus such as Ebola fever virus and Lassa fever virus, which are important global health issues resulting in significant morbidity and mortality $[3,4]$. Some kinds of medicine, extracorporeal membrane oxygenation (ECMO) and/or percutaneous cardiopulmonary support (PCPS) would be effective in COVID-19 pneumonia cases [5,6]. However, those effective managements for COVID-19 could NOT explain the regional difference of fatal rates as mentioned above. Therefore, we have hypothesized the explanation of the regional and age-related difference into "Dieting" as shown in Figure 1. The comprehensive fatality involves the integration of infection rate, an aggravation rate and a fatality rate. The comprehensive fatality of filovirus infections may be absolutely high [7], while that of COVID-19 may be different in several situations.

COVID-19 would enter the cells by attaching to the virus receptor, angiotensin-converting enzyme-2 (ACE2), being expressed on pneumocytes of the lower airways. The virus attaches to the ACE2 more easily at low $\mathrm{pH}$ values causing successful infection.

Therefore, acidic fluids such as gastric juice might happen to exacerbate the infection. In the patients with renal failure and/ or diabetes, COVID-19 infection would be more severe since the lower tissue-pH of the body because of acidosis from the diseases. In addition, it has been reported that the papain-like protease is essential for virus replication of SARS-CoV and is conserved among human coronaviruses [8]. So, several protease containing sour juice might exacerbate the COVID-19 infection, if those fluids would coexist in the airway. For example, some fruits and vegetables such as papaya, pineapple, and ginger richly contain robust proteases papain, bromelain, and zingipain, respectively. Does the coexistence in the airway happen so easily? Indeed, it does happen so easily by chance of snore, choke, aspiration, and in the patient of Gastro 
Esophageal Reflux Disease (GERD), those are very common in elder people and/or obesity. Recently, the prevalence of GERD is increasing in East Asia [9,10]. Dieting includes what to eat and/or what NOT to eat.

As the COVID-19 virus receptor ACE2 seems the counteracting enzyme of ACE, the ACE2 has been proven to be protective in various tissues. ACE2 converts angiotensin (Ang) II into Ang (1-7), which exerts its effects through the Mas receptor in numerous tissues including brain, heart, kidneys and so on. The ACE2/ Ang (1-7)/ Mas activates AKT signaling to improve inflammation and oxidative stress, which may also oppose to the Ang I-induced apoptosis.
Therefore, the regulation of the PI3K/AKT pathway is thought to correlate with host protection and disease prognosis. In case the COVID-19 virus terminates the ACE2/ Ang (1-7)/Mas/PI3K/ AKT protection pathway, it would be of significance to define appropriate strategies to achieve benefits to activate the PI3K/ AKT pathway. Yet the efficiency of pharmacological and/or vaccinal treatments against COVID-19 has been imperfect at present and might have unexpected side effects, dietary choices could indicate a certain role in the host-protection via the PI3K/AKT signaling activation.10 Lifestyle factors such as the ordinary diets could be currently playing certain roles against COVID-19 fatality anywhere on earth

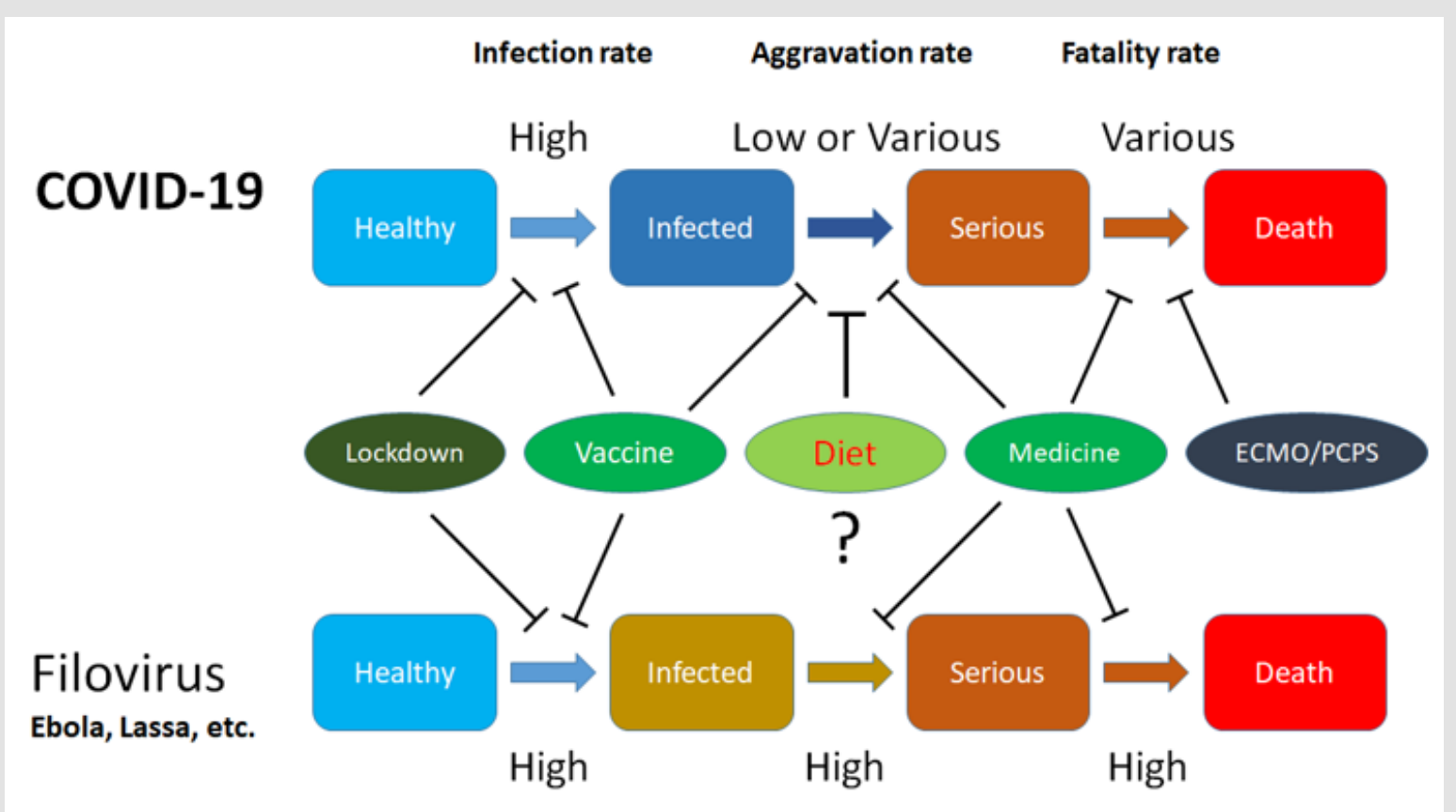

Figure 1: Schematic illustration implying that "Diet" as well as Vaccine, Medicine and ECMO/PCPS might inhibit the aggravation rate and/or fatality rate of COVID-19. In Filovirus infection such as Ebola fever or Lassa fever, on the other hand, comprehensive fatality rate may be high regardless of the "Diet". Lockdown might be effective in both cases. Hammerhead means inhibition.

\section{Financial Support and Sponsorship}

None

\section{Conflicts of Interest}

There are no conflicts of interest.

\section{Authorship Contributions}

Y.I. and S.M. conceived the subject of the review. Each author (Y.I., M.M., A.T., Y.K. and S.M.) had participated sufficiently in the work of drafting the article and/or revising the article for the rational content.

\section{References}

1. Bassetti M, Vena A, Giacobbe DR (2020) The novel Chinese coronavirus (2019-nCoV) infections: Challenges for fighting the storm. Eur J Clin Invest 50(3): e13209.
2. Rudan I (2020) A cascade of causes that led to the COVID-19 tragedy in Italy and in other European Union countries. J Glob Health 10(1): 010335 .

3. Peak CM, Wesolowski A, Zu Erbach-Schoenberg E, Tatem AJ, Wetter E, et al. (2018) Population mobility reductions associated with travel restrictions during the Ebola epidemic in Sierra Leone: use of mobile phone data. Int J Epidemiol 47(5): 1562-1570.

4. Welch SR, Guerrero LW, Chakrabarti AK, Mc Mullan LK, Flint M, et al. (2016) Lassa and Ebola virus inhibitors identified using minigenome and recombinant virus reporter systems. Antiviral Res. 136: 9-18.

5. Alemanno G, Tomaiuolo M, Peris A, Batacchi S, Nozzoli C, et al. (2020) Surgical perspectives and patways in an emergency department during the COVID-19 pandemic. Am J Surg.

6. Paital B, Das K, Parida SK (2020) Inter nation social lockdown versus medical care against COVID-19, a mild environmental insight with special reference to India. Sci Total Environ 23(728):138914.

7. M Isaäcson (2001) Viral hemorrhagic fever hazards for travelers in Africa.Isaäcson M.Clin Infect Dis 33(10): 1707-1712. 
8. Frieman M, Basu D, Matthews K, Taylor J, Jones G, et al. (2011) Yeast based small molecule screen for inhibitors of SARS-CoV. PLoS One 6(12) e28479.

9. Mousalreza Hosseini, Masoumeh Salari, Roshanak Salari (2015) Psyllium seed may be effective in the treatment of gastroesophageal

ISSN: 2574-1241

DOI: 10.26717/BJSTR.2020.28.004729

Satoru Matsuda. Biomed J Sci \& Tech Res

(C) (P) This work is licensed under Creative Commons Attribution 4.0 License

Submission Link: https://biomedres.us/submit-manuscript.php reflux disease (GERD) in patients with functional constipation (Journal of Medical Hypotheses and Ideas 9 (2): S4-S7.

10. Ikeda Y, Murakami M, Nakagawa Y, Tsuji A, Kitagishi Y, et al. (2020) Diet induces hepatocyte protection in fatty liver disease via modulation of PTEN signaling. Biomed Rep 12(6): 295-302.

$\begin{array}{ll}\text { BIOMEDICAL } & \text { Assets of Publishing with us } \\ \text { RESEARCHES } & \text { - Global archiving of articles } \\ \text { - Immediate, unrestricted online access }\end{array}$

